\title{
Effect of Systemic Arterial Hypertension on Retinal Nerve Fiber Layer and Macular Thickness
}

\author{
Mohamed M Rezk ${ }^{\text {a }}$, Ashraf A El-Shayeb ${ }^{\text {a }}$, Osama M Kamal ${ }^{\text {a }}$, Ahmed S Bayoumy ${ }^{\text {a }}$, Zeinab A Kasemy ${ }^{\text {b }}$
}

a

Department of ophthalmology, Benha faculty of medicine, Benha University, Egypt. b Department of Public health and community medicine, Menofia faculty of Medicine, Menofia University, Egypt

Correspondence to:Mohamed M Rezk, Department of ophthalmology, Benha faculty of medicine, Benha University, Egypt.

\section{Email:}

rezkophth@gmail.com

Received: 11 September, 2020

Accepted: 29 September, 2020

\begin{abstract}
:
Purpose: to investigate the changes in peri-papillary retinal nerve fiber layer thickness (RNFL) and macular thickness in patients with systemic arterial hypertension compared to normotensive control eyes.
\end{abstract}

Methods: This study included "40 eyes" of adult hypertensive patients (age $53.75 \pm 6.60$ years). The control group included "20 eyes" of age-matched participants with normal blood pressure. Peri-papillary (RNFL) and macular thickness were measured with Spectral Domain Optical Coherence Tomography (SD-OCT). Results: The mean duration of systemic hypertension was 7.07 \pm 1.68 years. Peri-papillary RNFL thickness was thinner at superior, inferior, nasal, temporal quadrants of RNFL and total RNFL thickness at hypertensive patient eyes group $(\mathrm{p}<0.001$ for all except nasal quadrant: $\mathrm{p}<0.007)$. Macular thickness was thinner at hypertensive patient eyes group ( $\mathrm{p}<0.001$ for all) compared to normotensive control eyes group. Conclusion: This study reported that both peri-papillary RNFL thickness and macular thickness showed significant thinning in patients with systemic arterial hypertension compared with healthy control eyes.

Keywords: Systemic hypertension; Retinal nerve fiber layer; Macular thickness; Hypertensive retinopathy. 


\section{Introduction:}

Systemic arterial hypertension is defined as a systolic blood pressure $\geq 140 \mathrm{mmHg}$ and/or diastolic blood pressure $\geq 90 \mathrm{mmHg}$ (1). It is a long-term condition in which the blood pressure is persistently elevated ${ }^{(2)}$. It is an established risk factor of atherosclerosis, ischemic events and associated with a higher risk of death. It affects one billion people worldwide, and it is considered as a major preventable cause of premature death and disability ${ }^{(3)}$.

The primary response of the retinal arterioles to systemic hypertension is vasoconstriction. Sustained hypertension leads to disruption of the inner blood retinal barrier, increased vascular permeability \& arteriolosclerosis. The fundus shows focal and generalized arteriolar narrowing, microaneurysms, flame shaped retinal hemorrhages, cotton-wool spots, hard exudates \& optic disc swelling ${ }^{(4)}$.

Signs of retinal damage caused by hypertension can be observed before target organ damage starts to manifest clinical symptoms in hypertensive patients. Statistically significant reductions in both macular and RNFL thickness were evident 1 year after the disappearance of the retinal changes evident during the early period of elevated blood pressure ${ }^{(5)}$.

Optical Coherence Tomography (OCT) is one of the most important non-invasive, reproducible and reliable ancillary tests for diagnosis of retinal pathology. It has allowed detailed quantitative analysis of retinal microstructure with high spatial resolution that has the advantage of segmenting the retina up to nine sector measurements rather than average thickness alone $^{(6)}$.

It can be used for evaluation of the peripapillary retinal nerve fiber layer (RNFL) and macular thickness and may provide a significant tool to improve the diagnosis, prognosis, and management of systemic hypertension in clinical practice ${ }^{(7)}$.

The aim of the study was to investigate changes in peri-papillary RNFL and macular thickness in patients with systemic arterial hypertension compared to normotensive control eyes.

\section{Subjects \&Methods:}

This retrospective cohort study was done at Benha university hospitals from November 2018 to August 2019. This study 
included "40 eyes" of adult hypertensive patients with hypertension duration of five years or more.

Informed consents were obtained from all participants. Exclusion criteria included any systemic disease other than systemic hypertension, past history of previous intraocular surgery, ocular trauma or ocular pathology other than hypertensive retinopathy. The control group included "20 eyes" of age-matched participants with normal blood pressure.

All patients and control subjects were subjected to the following:

-History taking (age, gender, occupation, past-medical history, past-surgical history \& ocular history).

-Referral to internal medicine outpatient clinic for clinical assessment including measurement of blood pressure.

-Complete ophthalmic examination of both eyes including: Best Corrected Visual acuity, objective refraction, intraocular pressure, slit lamp examination, motility examination, pupil reaction to light, color vision (red, green), fundus examination \& measurement of peri-papillary retinal nerve fiber layer thickness (RNFL) and macular thickness in both groups with Spectral
Domain Optical Coherence Tomography (SD-OCT): TOPCON 3D OCT-2000 device.

\section{Results}

The obtained results were tabulated \& statistically analyzed by the Statistical Package for Social Sciences, (SPSS version 20 - SPSS Inc., Chicago, IL, USA).

Mean duration of hypertension was 7.07 \pm 1.68 years. Difference in age between the two groups was insignificant $(p>0.05)$.So, both groups were age matched. Differences in BCVA and IOP between the two groups were insignificant as tabulated in (Table 1). Peri-papillary RNFL thickness was thinner at Superior, Inferior, Nasal, Temporal parts of RNFL and Average total RNFL thickness at Hypertensive patient eyes group compared to Normotensive control eyes group as tabulated in (Table 2).

Macular thickness was thinner at hypertensive patient eyes group (including Average Macular thickness, Central Macular thickness \&Total Macular Volume) compared to normotensive control eyes as tabulated in (Table 3).

The obtained results showed a significant positive correlation between total RNFL thickness and average macular thickness (Fig.1). Our results showed also a 
significant negative correlation between total RNFL thickness and duration of hypertension (Fig.2). The ROC Curve for Total RNFL thickness and Macular thickness is illustrated in (Fig.3). The validity of Total RNFL thickness, Total Macular Volume \& Average Macular Thickness is tabulated in (Table 4).

An Example of Hypertensive patient eyes group is shown in Fig. (4) and (5).

Table 1: Distribution of the studied groups regarding best corrected visual acuity (BCVA) and intraocular pressure (IOP):

\begin{tabular}{|c|c|c|c|c|}
\hline & Gro & ups & & \\
\hline & $\begin{array}{c}\text { Hypertensive patient eyes } \\
\text { No. }=40 \text { eyes } \\
\text { Mean } \pm \text { SD }\end{array}$ & $\begin{array}{c}\text { Normotensive control eyes } \\
\text { No. }=20 \text { eyes } \\
\text { Mean } \pm \text { SD }\end{array}$ & $\begin{array}{l}\text { Test of } \\
\text { significance }\end{array}$ & $P$ value \\
\hline Age (Year) & $53.75 \pm 6.60$ & $54.0 \pm 7.86$ & $\mathrm{t}=\mathbf{0 . 1 3}$ & 0.897 \\
\hline $\begin{array}{l}\text { Duration of } \\
\text { hypertension (Year) }\end{array}$ & $7.07 \pm 1.68$ & - & - & - \\
\hline $\begin{array}{l}\text { Gender } \\
\text { Male } \\
\text { Female }\end{array}$ & $\begin{array}{c}\text { Number } \\
9 \\
11\end{array}$ & $\begin{array}{c}\text { Percent \% } \\
45.0 \\
55.0\end{array}$ & $\begin{array}{c}\text { Number } \\
5 \\
5\end{array}$ & $\begin{array}{c}\text { Percent } \\
\% \\
50.0 \\
50.0\end{array}$ \\
\hline BCVA & $0.83 \pm 0.13$ & $0.82 \pm 0.10$ & $\begin{array}{l}\text { Mann-Whitney } \\
=0.43\end{array}$ & 0.663 \\
\hline IOP & $15.52 \pm 2.02$ & $15.55 \pm 1.82$ & $t=0.04$ & 0.963 \\
\hline
\end{tabular}

Table 2: Distribution of the studied groups regarding Retinal nerve fiber layer (RNFL) thickness:

\begin{tabular}{lllll}
\hline $\begin{array}{l}\text { RNFL } \\
\text { thickness }(\boldsymbol{\mu m})\end{array}$ & $\begin{array}{l}\text { Groups } \\
\text { Hypertensive patient eyes } \\
\text { No.= 40 eyes } \\
\text { Mean } \pm \text { SD }\end{array}$ & $\begin{array}{l}\text { Normotensive control eyes } \\
\text { No.= 20 eyes } \\
\text { Mean } \pm \text { SD }\end{array}$ & $\begin{array}{l}\text { Test } \\
\text { significance }\end{array}$ & \\
& $121.45 \pm 12.45$ & $150.40 \pm 14.33$ & of & P value \\
\hline Superior & 120.0 & 152.50 & $=\mathbf{5 . 3 0}$ & \\
Median & $112.25-128$ & $138.5-159.5$ & & \\
IQR & $125.07 \pm 12.09$ & $142.15 \pm 14.57$ & $\mathbf{t = 4 . 8 1}$ & $<\mathbf{0 . 0 0 1}^{*}$ \\
Inferior & $81.82 \pm 17.75$ & $94.60 \pm 14.16$ & $\mathbf{t}=\mathbf{2 . 7 9}$ & $\mathbf{0 . 0 0 7 * *}$ \\
Nasal & $70.82 \pm 14.33$ & $84.15 \pm 12.45$ & $\mathbf{M a n n}-$ Whitney & $<\mathbf{0 . 0 0 1 *}$ \\
Temporal & 67.5 & 86.0 & $\mathbf{= 3 . 5 4}$ & \\
Median & $62.5-79.5$ & $72-75$ & & $\mathbf{t}$ \\
IQR & $99.57 \pm 6.23$ & $116.85 \pm 6.34$ & $\mathbf{0 . 0 4}$ & $<\mathbf{0 . 0 0 1 *}$ \\
Total(Average) & &
\end{tabular}

*significant **highly significant 
Table 3: Distribution of the studied groups for macular thickness:

\begin{tabular}{|c|c|c|c|c|}
\hline \multirow[t]{3}{*}{ Macular indices } & \multicolumn{2}{|c|}{ Groups } & \multirow{3}{*}{$\begin{array}{l}\text { Test of } \\
\text { significance }\end{array}$} & \multirow{3}{*}{ P value } \\
\hline & Hypertensive patient & Normotensive control & & \\
\hline & eyes No. $=40$ eyes & No. $=20$ eyes & & \\
\hline & Mean \pm SD & Mean \pm SD & & \\
\hline Average Macular thickness $(\boldsymbol{\mu m})$ & $263.22 \pm 12.51$ & $280.49 \pm 7.95$ & $\mathrm{t}=\mathbf{5 . 6 1}$ & $<0.001 *$ \\
\hline Central Macular thickness $(\mu \mathrm{m})$ & $204.75 \pm 26.39$ & $229.50 \pm 14.17$ & Mann- & $<0.001 *$ \\
\hline Median & 204 & 230 & Whitney & \\
\hline IQR & $183.5-217.50$ & $219.25-236.0$ & $=4.02$ & \\
\hline Total Macular Volume $\left(\mathrm{mm}^{3}\right)$ & $7.45 \pm 0.35$ & $7.93 \pm 0.22$ & $\mathrm{t}=6.29$ & $<0.001 *$ \\
\hline
\end{tabular}

*highly significant

Table 4: The Validity of Total RNFL thickness, Total Macular Volume \& Average Macular Thickness:

\begin{tabular}{|c|c|c|c|c|c|c|c|c|}
\hline Variable & & AUC & $\begin{array}{l}\text { Cut-off } \\
\text { point }\end{array}$ & $\begin{array}{l}\text { Sensitivity } \\
\% \\
\end{array}$ & $\begin{array}{l}\text { Specificity } \\
\% \\
\end{array}$ & $\begin{array}{l}\text { Accuracy } \\
\% \\
\end{array}$ & $\begin{array}{l}\text { PPV } \\
\% \\
\end{array}$ & $\begin{array}{l}\text { NPV } \\
\% \\
\end{array}$ \\
\hline $\begin{array}{l}\text { Total } \\
\text { thickness }\end{array}$ & RNFL & 0.976 & $<85$ & 97.5 & 100.0 & 98.3 & 100.0 & 95.2 \\
\hline $\begin{array}{l}\text { Total } \\
\text { Volume }\end{array}$ & Macular & 0.864 & $<6.75$ & 97.5 & 100.0 & 98.3 & 100.0 & 95.2 \\
\hline $\begin{array}{l}\text { Average } \\
\text { thickness }\end{array}$ & Macular & 0.868 & $<238.9$ & 97.5 & 100.0 & 98.3 & 100.0 & 95.2 \\
\hline
\end{tabular}

AUC: Area under the Curve, PPV: Positive Predictive Value, NPV: Negative Predictive Value.

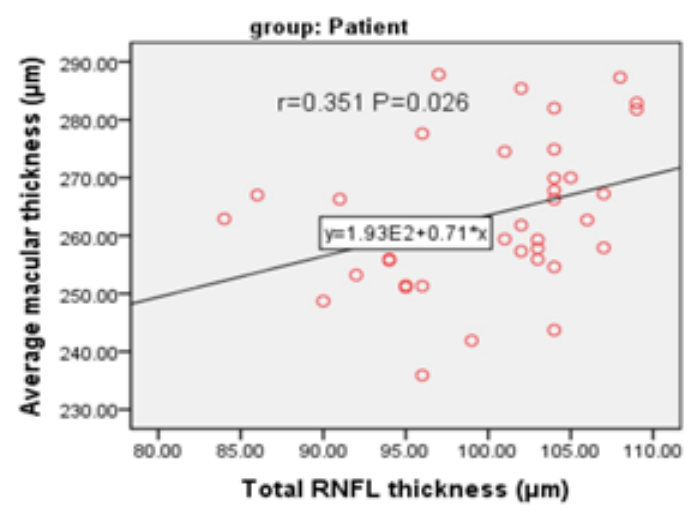

Fig.1: Significant positive correlation between total RNFL thickness and average macular thickness 


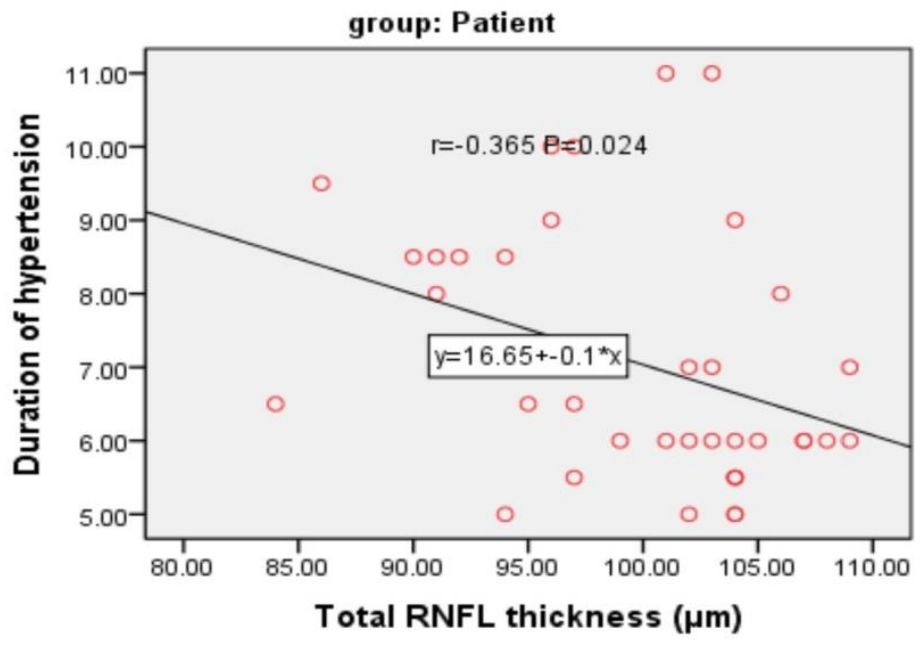

Fig.2: Significant negative correlation between total RNFL thickness and duration of hypertension

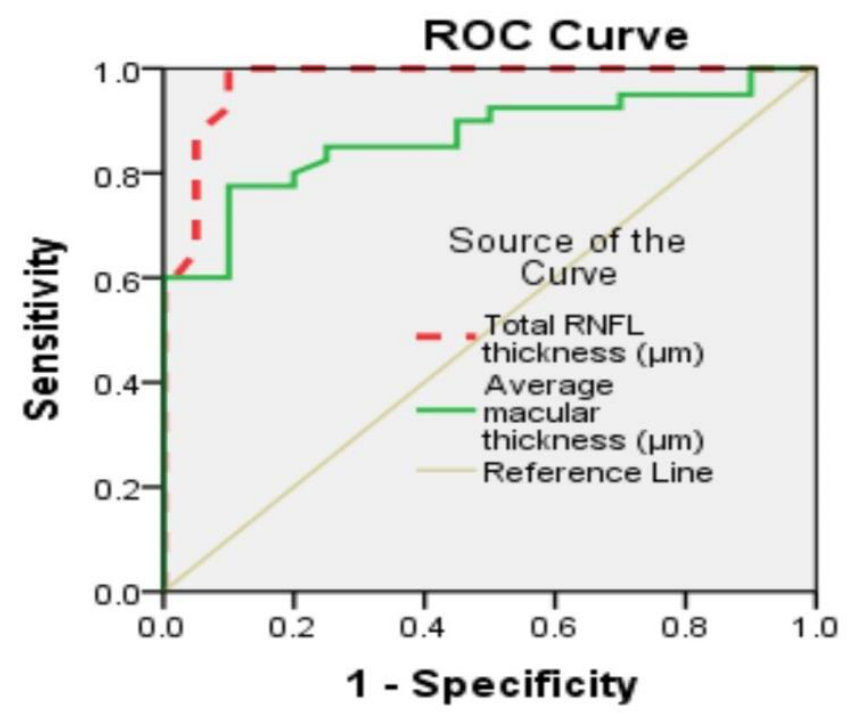

Fig.3: ROC Curve for Total RNFL thickness and Average Macular thickness 


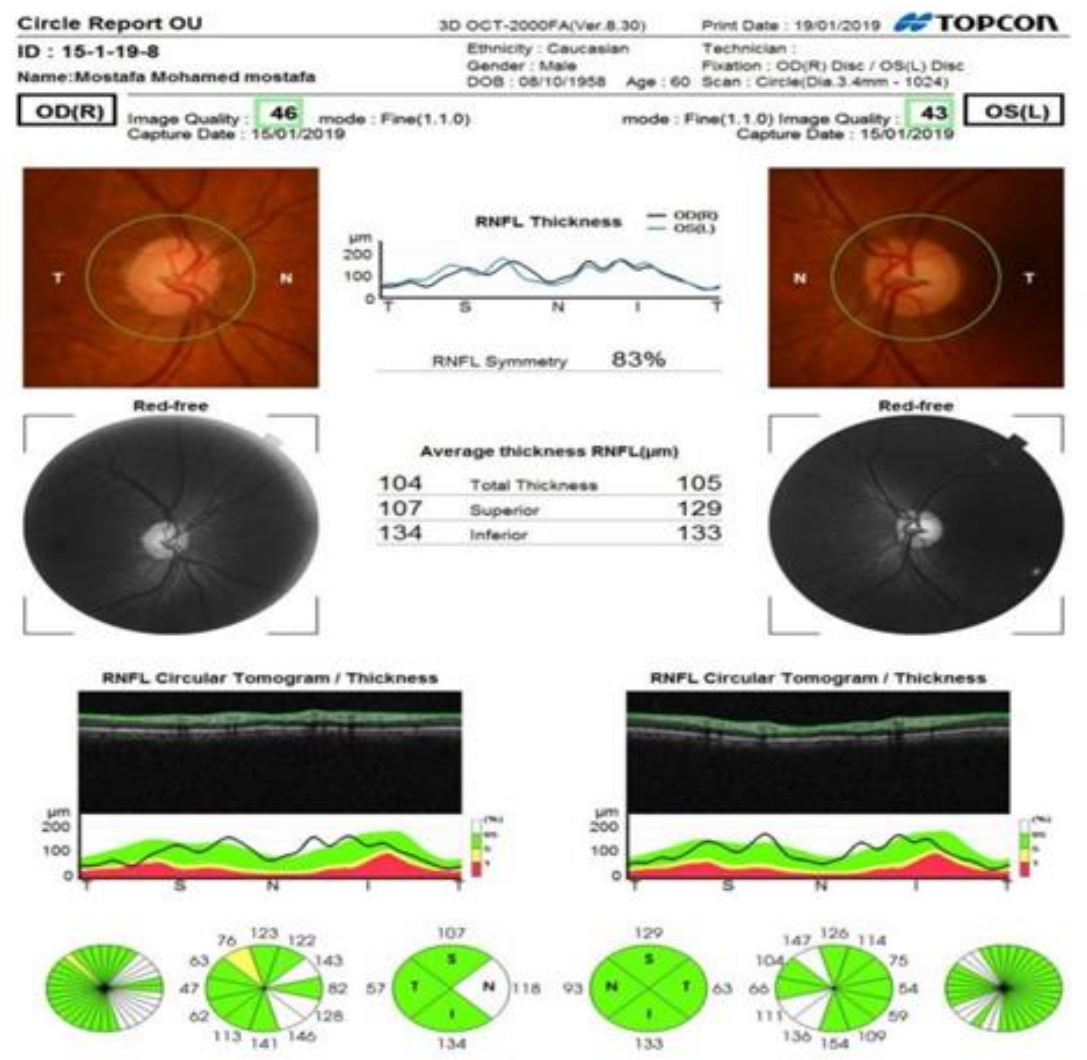

Fig.4: OCT peripapillary RNFL of RT \& LT eyes

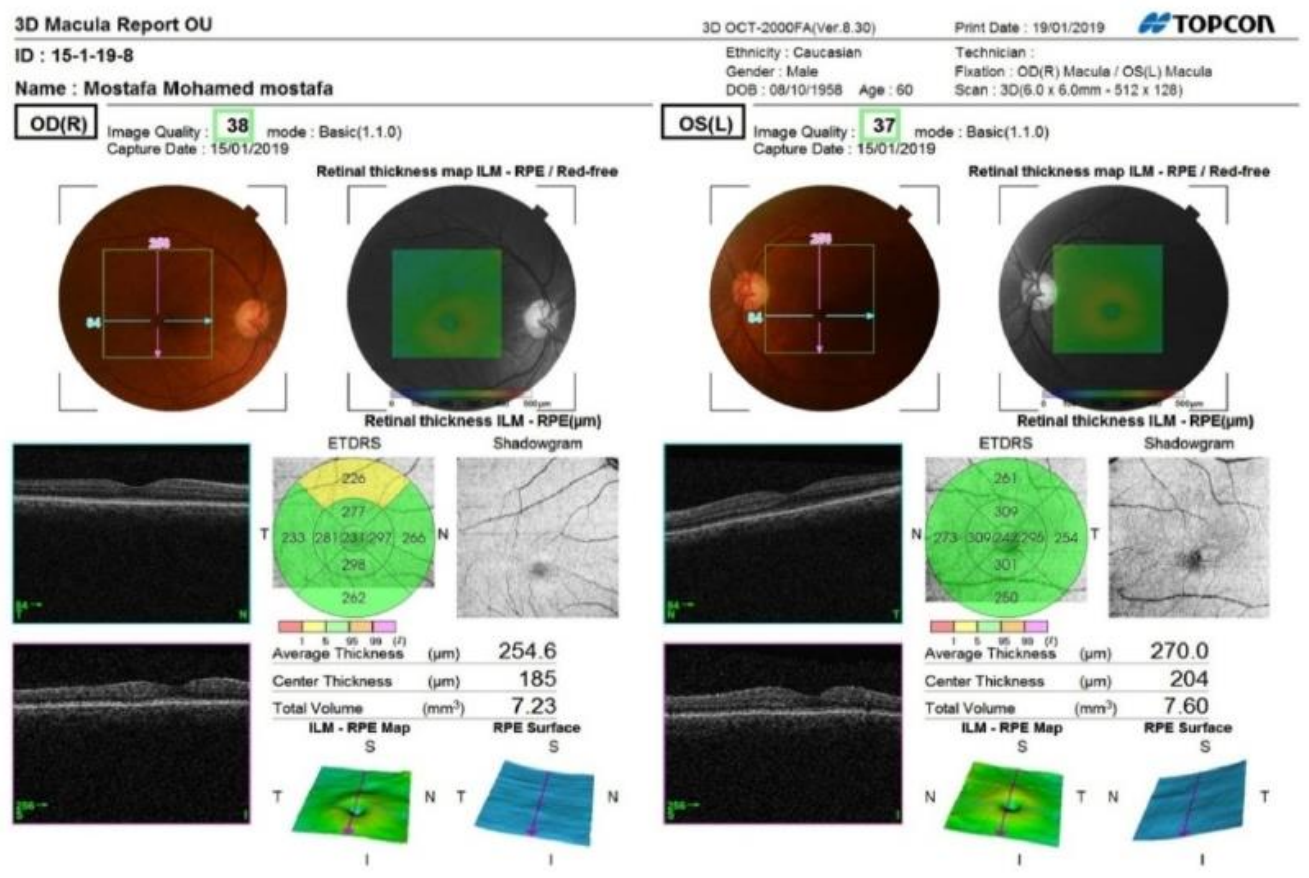

Fig.5: OCT macula of RT \& LT eyes 


\section{Discussion:}

Hypertension is a major cause of morbidity and mortality ${ }^{(8)}$. The effects of arterial hypertension can be directly visualized in the fundus. These changes may involve the retinal arterioles, the choroid, and the optic nerve. Observation of these fundus changes may lead to a diagnosis of hypertension in a previously undiagnosed patient ${ }^{(9)}$.

Optical coherence tomography (OCT) has revolutionized our ability to visualize structural abnormalities in the retina. Spectral-domain OCT (SD-OCT) provides significantly better image resolution, allowing detailed images of retinal morphologic features to be obtained ${ }^{(\mathbf{1 0})}$.

The probable mechanism of macular thinning associated with systemic hypertension without exudative retinopathy is auto-regulation of retinal blood vessels induced by increased blood pressure, followed by vascular constriction and mild reduction in macular thickness and volume. Systemic blood pressure was associated with a smaller diameter of the central retinal $\operatorname{arteriole}^{(\mathbf{1 1})}$.

It was found that hypertensive patients had a significantly thinner macular thickness at most subfields, except for the fovea. Such arteriolar change influenced macular thickness. Macular thickness at the central subfield showed less affection with systemic hypertension because the central subfield is an avascular area (foveal avascular zone), which might be less affected by hypertensive vascular changes ${ }^{(\mathbf{1 2})}$.

It was reported that ganglion cell complex thickness decrease is possibly a better retinal marker for arterial hypertensive changes with respect to RNFL and macular thickness. One of the highest RNFL thickness decreases was found in the inner temporal region. Nasal subfields did not correlate significantly with clinical parameters. The temporal subfields are the primarily affected sites in patients with systemic hypertension.

The distance between the temporal subfield areas and optic disc is more than the distance between optic disc and superior, inferior, and nasal subfields. The calibers of retinal arteries are decreased towards the periphery ${ }^{(13)}$.

It may be hypothesized that the narrower retinal arterioles that supply the temporal subfields may be affected more severely in systemic hypertension than larger retinal 
arterioles that nourish nasal subfields. For this reason, the ischemia caused by systemic hypertension in temporal subfields may cause more severe cell damage and loss in the retina ${ }^{(\mathbf{1 3})}$.

A study reported that RNFL thickness and CMT were significantly thinner in the patients with hypertensive retinopathy than in the normal control group. The impact of retinal changes associated with systemic disease such as hypertension should therefore be considered when characterizing the thickness of the RNFL and central macula in ocular disorders ${ }^{(\mathbf{1 4})}$.

In addition, in a study 59 patients were enrolled with essential hypertension (mean age: $53.62 \pm 10.7$ years) and age-matched 54 healthy subjects (mean age: $51.0 \pm 8.18$ years). They reported that RNFL thickness of hypertensive patients was thinner than healthy controls. They suggested that particularly superior and inferior quadrants of retinal nerve are affected in systemic hypertension ${ }^{(15)}$, which agreed with our results.

In another study it was reported that localized retinal nerve fiber layer defects addition to retinal micro-vascular abnormalities including localized and generalized arteriolar thinning, arteriovenous nicking and a lower arteriolar/venular diameter ratio, were associated with different grades of arterial hypertension and may be used as a retinal marker of arterial hypertension ${ }^{(\mathbf{1 6})}$. The obtained results of our study showed a highly significant decrease $(\mathrm{p}<0.001$ for all) in the superior, inferior, temporal parts of peri-papillary RNFL thickness and Average total RNFL thickness, the thickness of nasal part of peri-papillary RNFL which was significantly decreased $(\mathrm{p}<0.007$ for all $)$ at hypertensive patient eyes group compared to normotensive control eyes.

Macular thickness (including Average Macular thickness, Central Macular thickness \& Total Macular Volume) showed a highly significant decrease $(\mathrm{p}<0.001$ for all) at hypertensive patient eyes group compared to normotensive control eyes. These results came in accordance with most of previous investigators.

\section{Conclusion}

This study reported that both peri-papillary RNFL thickness and macular thickness showed significant thinning in patients with systemic arterial hypertension compared with healthy control eyes. This study confirmed the importance of OCT in monitoring of hypertensive retinopathy. 


\section{References}

1-Victor RJ: Arterial hypertension. In: "GoldmanCecil Medicine" 25 ${ }^{\text {th }}$ edition: 2014; P.381-397. Elsevier Saunders, USA.

2- Naish J \& Court DS: CVS system, in: "Medical Sciences" (3rd ed.), 2019; Ch.11. P.483-556. Elsevier Saunders, Poland.

3- Ali F, Tacey M, Lykopandis N, Colville D, Lamoureux E, Wong TY et al.: Micro-vascular narrowing and BP monitoring: A single center observational study, PLOS ONE 2019;14 (3).

4- Kanski JJ \& Bowling B: Retinal vascular disease: hypertensive eye disease. In: "Clinical Ophthalmology: a Systematic Approach" 2016; $8^{\text {th }}$ ed.: P.557-559. Elsevier Saunders: Edinburgh, London.

5- Lee HM, Lee WH, Kim KN, Jo YJ, Kim JY. Changes in thickness of central macula and retinal nerve fibre layer in severe hypertensive retinopathy: a 1-year longitudinal study. Acta ophthalmologica. 2018 May;96(3):e386-92.

6- Bruce A, Pacey IE, Dharni P, Scally AJ \& Barrett BT: Repeatability and reproducibility of macular thickness measurements using fourier domain optical coherence tomography, The open ophthalmology journal 2009;3:10-14.

7- Konstantinidis L \& Guex-Crosier Y: Hypertension and the eye, Current Opinion in Ophthalmology 2016; 27(6):514-521.

8- Addo J, Smeeth L \& Leon DA: Hypertensive target organ damage in Ghanaian civil servants with hypertension. PLOS One 2009; 18; 4(8):e6672.

9- Baker ML, Hand PJ, Wang JJ \& Wong TY: Retinal signs and stroke: revisiting the link between the eye and brain, Stroke 2008; 39(4):1371- 1379.
10- Suzuki M, Minamoto A, Yamane K, Uka J, Aoki $\mathrm{S} \&$ Mishima HK: Malignant hypertensive retinopathy studied with optical coherence tomography. Retina 2005; 25:383-384.

11- Klein R, Myers CE, Knudtson MD ,Lee KE, Gangnon R, Wong TY \& Klein BE: Relationship of blood pressure and other factors to serial retinal arteriolar diameter measurements over time: the beaver dam eye study. Arch Ophthalmol. 2012; 130:1019-1027.

12- Kong M, Kwun Y, Sung J, Ham DI \& Song YM: Association between systemic hypertension and macular thickness measured by Optical Coherence Tomography. Invest Ophthl Vis Sci. 2015; 56(4):2144-2150.

13- Akay F, Gündoğan FC, Yolcu U,Toyran S, Tunç E \& Uzun S: Retinal structural changes in systemic arterial hypertension: an OCT study. Eur J Ophthalmol; 2016; 26 (5): 436-441.

14- Lee SH, Lee WH, Lim HB, Jo YJ \& Kim JY: Thicknesses of central macular, retinal nerve fiber and ganglion cell inner plexiform layers in patients with hypertension. The journal of retinal and vitreous diseases: 2018; 1-9.

15- Sahin OZ, Sahin SB, Ayaz T, Karadag $\underline{\text { Z, Turkyilmaz K}}$, Aktas E \& Bostan M: The impact of hypertension on retinal nerve fiber layer thickness and its association with carotid intima media thickness, Blood Pressure, 2015; 24 (3):178-184.

16- Xu L, Zhou JQ, Wang S, Wang YX, You QS, Yang $\mathrm{H}$ et al.: Localized retinal nerve fiber layer defects and arterial hypertension. American Journal of Hypertension; 2013; 26(4):511-517.

To cite this article: Mohamed M Rezk, Ashraf A El-Shayeb, Osama M Kamal, Ahmed S Bayoumy, Zeinab A Kasemy Effect of Systemic Arterial Hypertension on Retinal Nerve Fiber Layer and Macular Thickness. BMFJ 2020; (surgical issue): 66-75. DOI: 10.21608/bmfj.2020.16843.1055 